\title{
Evaluation of Light Pollution in Global Protected Areas from 1992 to 2018
}

\author{
Haowei Mu ${ }^{1}(\mathbb{D})$ Xuecao Li ${ }^{1,2, * \mathbb{D}}$, Xiaoping Du ${ }^{3} \mathbb{D}$, Jianxi Huang ${ }^{1,2} \mathbb{D}$, Wei Su ${ }^{1,2} \mathbb{D}$, Tengyun Hu ${ }^{4}$, Yanan Wen ${ }^{1,5}$, \\ Peiyi Yin ${ }^{1}$, Yuan Han $^{3}$ and Fei Xue ${ }^{6}$
}

check for updates

Citation: Mu, H.; Li, X.; Du, X.; Huang, J.; Su, W.; Hu, T.; Wen, Y.; Yin, P.; Han, Y.; Xue, F. Evaluation of Light Pollution in Global Protected Areas from 1992 to 2018. Remote Sens. 2021, 13, 1849. https://doi.org/10.3390/ rs13091849

Academic Editor: Martin Aubé

Received: 24 March 2021

Accepted: 6 May 2021

Published: 9 May 2021

Publisher's Note: MDPI stays neutral with regard to jurisdictional claims in published maps and institutional affiliations.

Copyright: (c) 2021 by the authors. Licensee MDPI, Basel, Switzerland. This article is an open access article distributed under the terms and conditions of the Creative Commons Attribution (CC BY) license (https:// creativecommons.org/licenses/by/ $4.0 /)$.
1 College of Land Science and Technology, China Agricultural University, Beijing 100083, China; 0218742@stu.lzjtu.edu.cn (H.M.); jxhuang@cau.edu.cn (J.H.); suwei@cau.edu.cn (W.S.); 0218752@stu.lzjtu.edu.cn (Y.W.); peiyiyin@163.com (P.Y.)

2 Key Laboratory of Remote Sensing for Agri-Hazards, Ministry of Agriculture and Rural Affairs, Beijing 100083, China

3 Key Laboratory of Digital Earth Science, Institute of Remote Sensing and Digital Earth, Chinese Academy of Sciences, Beijing 100094, China; duxp@radi.ac.cn (X.D.); hanyuan@aircas.ac.cn (Y.H.)

4 Beijing Municipal Institute of City Planning and Design, Beijing 100045, China; hutengyun@bmicpd.com.cn

5 Faculty of Geomatics, Lanzhou Jiaotong University, Lanzhou 730070, China

6 Faculty of Architecture, Civil and Transportation Engineering, Beijing University of Technology, Beijing 100000, China; xuefei@BJUT.edu.cn

* Correspondence: xuecaoli@cau.edu.cn

\begin{abstract}
Light pollution, a phenomenon in which artificial nighttime light (NTL) changes the form of brightness and darkness in natural areas such as protected areas (PAs), has become a global concern due to its threat to global biodiversity. With ongoing global urbanization and climate change, the light pollution status in global PAs deserves attention for mitigation and adaptation. In this study, we developed a framework to evaluate the light pollution status in global PAs, using the global NTL time series data. First, we classified global PAs $(30,624)$ into three pollution categories: non-polluted (5974), continuously polluted (8141), and discontinuously polluted $(16,509)$, according to the time of occurrence of lit pixels in/around PAs from 1992 to 2018. Then, we explored the NTL intensity (e.g., digital numbers) and its trend in those polluted PAs and identified those hotspots of PAs at the global scale with consideration of global urbanization. Our study shows that global light pollution is mainly distributed within the range of $30^{\circ} \mathrm{N}$ and $60^{\circ} \mathrm{N}$, including Europe, north America, and East Asia. Although the temporal trend of NTL intensity in global PAs is increasing, Japan and the United States of America (USA) have opposite trends due to the implementation of well-planned ecological conservation policies and declining population growth. For most polluted PAs, the lit pixels are close to their boundaries (i.e., less than $10 \mathrm{~km}$ ), and the NTL in/around these lit areas has become stronger over the past decades. The identified hotspots of PAs (e.g., Europe, the USA, and East Asia) help support decisions on global biodiversity conservation, particularly with global urbanization and climate change.
\end{abstract}

Keywords: nighttime light; urban sprawl; nighttime light intensity; biodiversity conservation

\section{Introduction}

Artificial light pollution is a general environmental concern by changing the natural form of brightness and darkness in the ecosystem, which further affects the phenology of insects and biodiversity in ecosystems [1], especially in protected areas (PA). The nighttime light (NTL) reflects human activities and can be monitored by satellites [2]. Given the rapid global urbanization $[3,4]$, NTL has imposed noticeable pressures on natural systems and wildlife, causing ecological problems such as artificial light pollution [5]. PA plays a crucial role in global biodiversity conservation [6] and has been extensively used in international programs such as the Aichi biodiversity targets [7] and Sustainable Development Goals (SDGs) [8,9]. In these programs, PAs were regarded as critical elements to maintain the 
ecological environment and the diversity of species [10,11]. However, limited attention has been paid to the global light pollution of PA, given that we are entering a rapid global urbanization era [12,13]. In general, light pollution has been increasing in most terrestrial ecosystems over the past decades, resulting in considerable impacts on species' habitats and biodiversity conservation [14]. Artificial light has been shown to have ecological effects with different brightness, changing the natural light cycle and affecting its biodiversity $[15,16]$. For example, light pollution affects the population of insects $[17,18]$, the supply of ecosystem services [19], and reduces the physiological effect and reproductive yield of plants $[20,21]$. As such, studies on light pollution for biodiversity conservation are urgent $[5,22]$. Meanwhile, due to rapid global urbanization, the artificial light in/around PAs has increased significantly and threatened the biodiversity in nearby PAs [23].

Although the global expansion of human activity (e.g., urban sprawl) has posed a noticeable impact on wildlife in PAs, this impact can be quantified by combining remotesensing observations and ecological models to support sustainable ecological development conservation strategies $[2,24]$. The NTL time series data are widely used to characterize the intensity and change of socioeconomic activities [25,26]. Hence, the NTL data provide an avenue to evaluate the impact of anthropogenic activities in global PAs [27,28]. From the perspective of biodiversity conservation, NTL can quantify the impact of artificial light on biodiversity loss [29], therefore enabling a host of applications such as habitat fragmentation and loss [30], resource extraction, and human-natural conflicts [31]. As a result, studies on biodiversity conservation using NTL time series data have become a rapidly growing field over the past decades [32].

Previously published studies on NTL impacts on PAs are limited in temporal trend analysis and spatial pattern identification. Given that artificial light can cause habitat degradation, many relevant studies on light pollution have been conducted [33-36]. To the best of our knowledge, most existing studies focused on statistical analyses of NTL in PAs and the temporal span is limited to 2013 or earlier [23,35-37], or local surveys in particular areas [38,39] as well as in the ocean [40]. It is essential to understand the spatial relationship between the NTL and PAs for better conservation of global ecological environments [41], by mapping the lit areas in/around PAs and characterizing their temporal trends. As such, long-term and temporally consistent NTL time series data are highly required to support these studies to better understand the temporal trends of light pollution in/around worldwide PAs.

To address these challenges, we investigated the global distribution of light pollution in global PAs. Three different categories (i.e., non-polluted, continuously polluted, and discontinuously polluted) of NTL pollution in PAs were identified. The temporal trend of NTL in/around these polluted PAs was explored. The remainder of this paper is organized as follows: Section 2 and 3 describe the datasets and methods used in this study, respectively; Section 4 presents the results, and Section 5 gives a discussion on some topics related to light pollution; Section 6 ends with the conclusion.

\section{Datasets}

\subsection{The Global Protected Area}

We used the world database on protected areas (WDPA) to evaluate the influence of light pollution on PAs. The WDPA has been widely used for the evaluation of global ecological zones [42], supporting global ecological protection and development targets (e.g., the Aichi Target [43] and the SDGs) [44,45]. This dataset provides information on the location and spatial extent of the PAs worldwide [46]. The International Union for Conservation of Nature (IUCN) defines different PA types in the WDPA dataset, including strict nature reserve (Ia), wilderness area (Ib), national park (II), natural monument of feature (III), habitat/species management area (IV), protected landscape/seascape (V), and protected area with sustainable use of natural resources (VI). Given that there are many small PAs worldwide, we excluded those PAs in the ocean with areas less than $10 \mathrm{~km}^{2}$. In total, more than 30,000 PAs were used in our study. 


\subsection{The Harmonized Global Nighttime Light Data}

We collected the harmonized global NTL data from 1992 to 2018 as our primary data source of light pollution [2,47]. The harmonized NTL data integrate satellite observations from the Defense Meteorological Satellite Program Operational Line-scan System (DMSP/OLS) and the Visible Infrared Imaging Radiometer Suite Day Night Band (VIIRS/DNB) data. The temporal spans of DMSP and VIIRS NTL data are from 1992 to 2013 and from 2012 to 2018 , respectively, with a near-global coverage (i.e., $65^{\circ} \mathrm{S}$ to $75^{\circ} \mathrm{N}$ ) [48]. The raw records in DMSP NTL data are digital number (DN) values (i.e., ranging from 0 to 63), notably different from the radiance in the VIIRS/DNB data. Additionally, their spatial resolutions are different, i.e., 30-arc and 15-arc in DMSP/OLI and VIIRS/DNB, respectively. To extend the interval of DMSP NTL observations, the harmonized global NTL data were generated using the kernel density approach $[26,49]$ and the sigmoid function, which aggregates the 15-arc resolution to 30-arc seconds and converts annual VIIRS observations to the DMSP-like NTL data [2], respectively. Given that there are more uncertainties when the DNs in NTL data are lower, we screened out pixels with DN values less than 7 in our study as suggested in [2].

\section{Methodology}

We evaluated the light pollution of global PAs from 1992 to 2018 using the harmonized NTL and the WDPA data (Figure 1). First, we categorized all PAs as three major types of light pollution: continuously polluted PAs, discontinuously polluted PAs, and nonpolluted PAs (Figure 1a). Then, we investigated the temporal trend of NTL in polluted PAs (i.e., continuously and discontinuously), where the NTL change in different regions around the PA was explored (Figure 1b). Details of the definition and temporal trends of NTL are presented in the following sections.

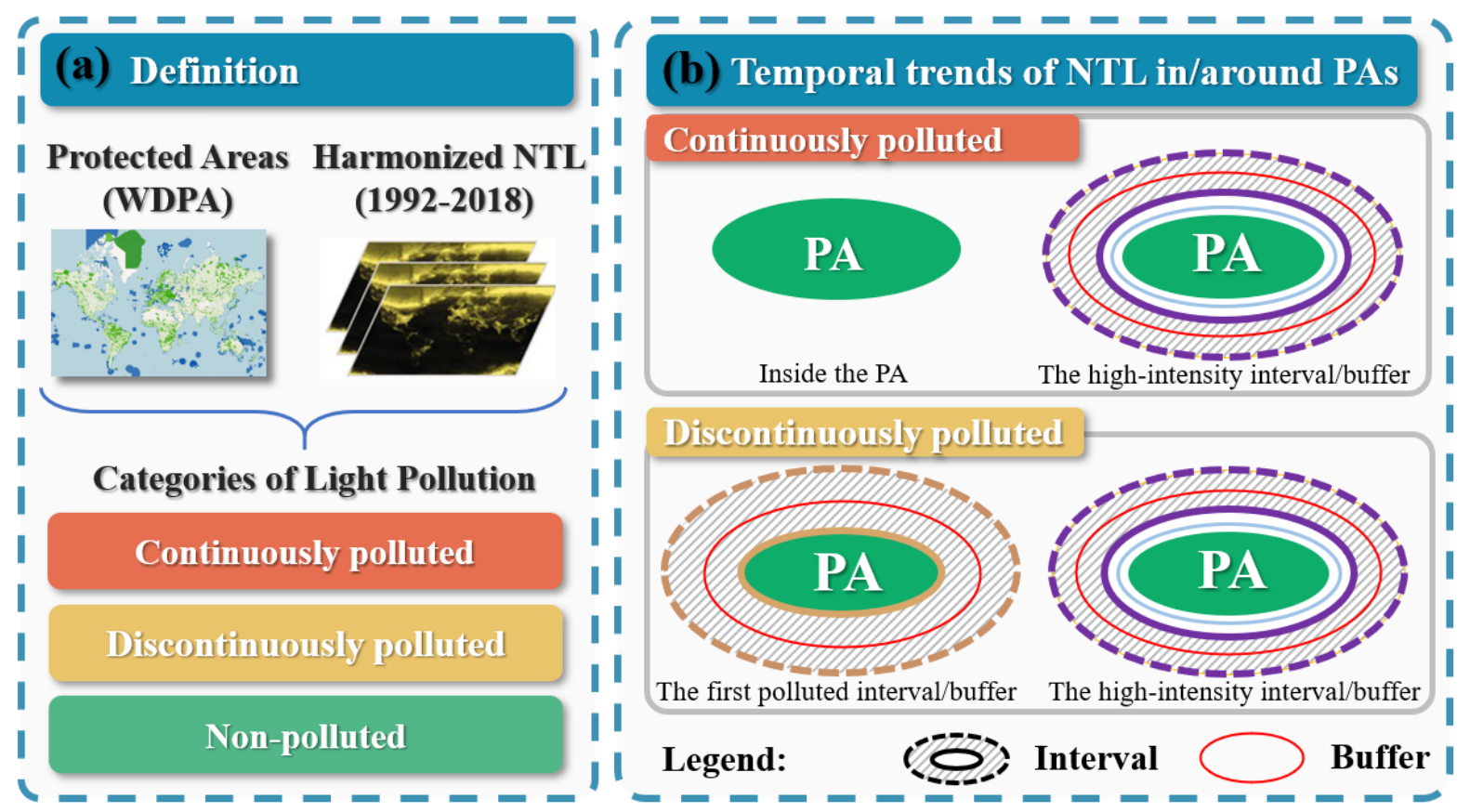

Figure 1. The proposed analyses framework of light pollution in global PAs by combining different light pollution categories (a) and the temporal trend of NTL in polluted PAs (b). Note: PAs are simplified as ellipses for illustration.

\subsection{Definition of Light Pollution Categories}

We classified all PAs as three major types according to the spatial extent and year of lit pixels in/around them (Figure 2). The definition of light pollution in our study is the occurrence of NTL light within the $50 \mathrm{~km}$ buffer zone of PA, as suggested in [36]. The first 
is PAs without any lit pixels (non-polluted) inside the PA during the whole period (1992 to 2018) (Figure 2a). By contrast, the second is continuously polluted PAs, which have had lit pixels in and around their buffer zones since 1992 (Figure 2b). A representative of this pollution category can be referred to as the case in Paris (Figure S1), where the mean NTL around these PAs has been continuously increasing since the 1990s. Unlike those continuously polluted PAs, the discontinuously polluted PAs have lit pixels around during the middle of period 1992 to 2018, as illustrated in the case of Zhangjiajie (China) (Figure S2) due to the rapid urban sprawl process. Considering that most non-polluted PAs are distributed in high-latitude regions, we focused on these polluted types (i.e., the continuously and discontinuously polluted).

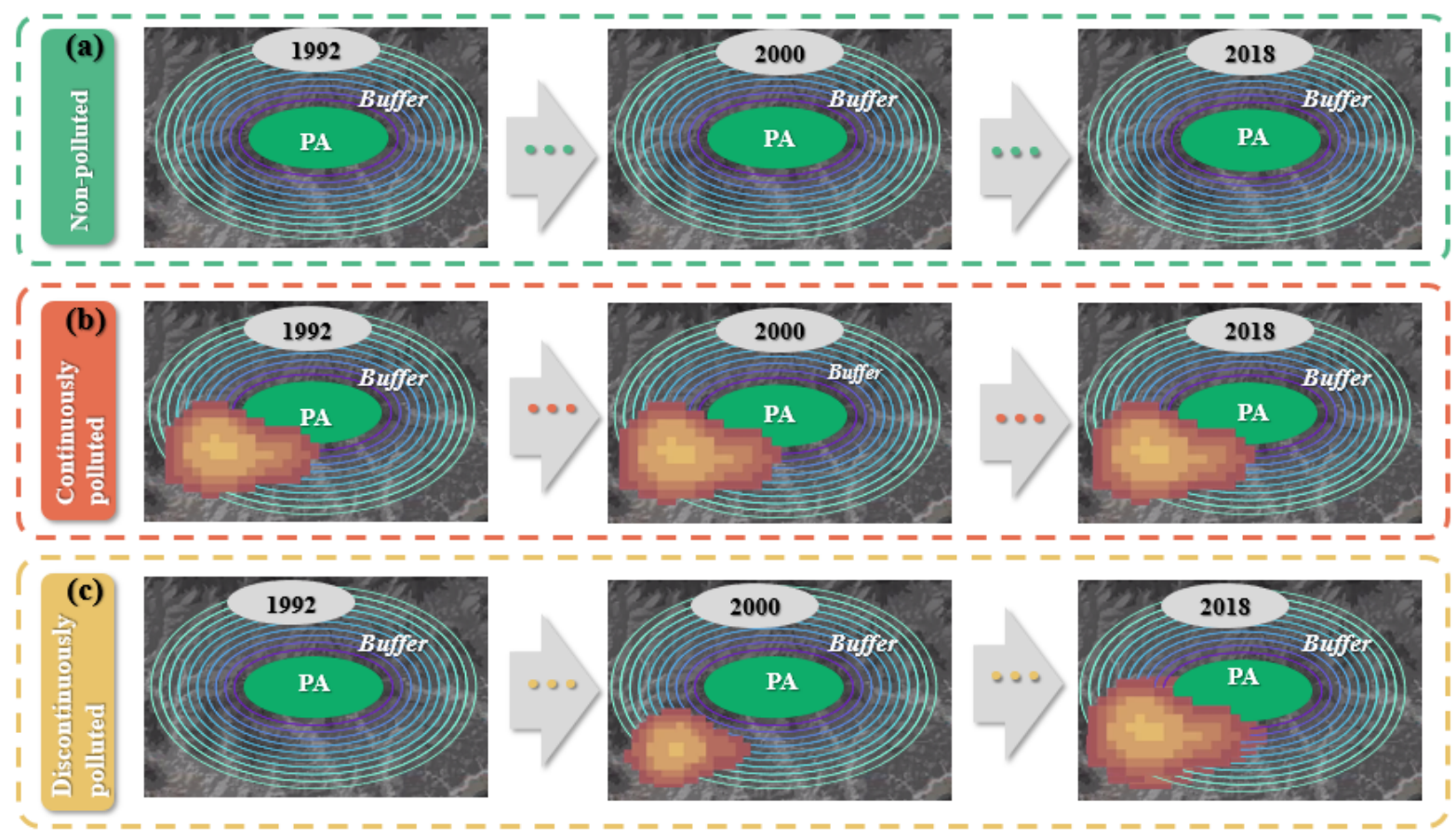

Figure 2. Conceptual illustration of light pollution categories of non-polluted (a), continuously polluted (b), and discontinuously polluted (c).

\subsection{The Temporal Trends of Nighttime Light}

We explored the temporal trend of NTL change using the Theil-Sen slope and MannKendall test in polluted PAs (i.e., continuously and discontinuously polluted). We measured the slope of NTL change using the Theil-Sen trend approach, a robust and simple linear regression method [50]. We also calculated the significance level using the $p$-value provided by the Mann-Kendall approach [51]. Combining these two approaches for trend analyses is extensively used in studies such as ecological and environmental change [52,53].

To identify those buffers with lit pixels that have different NTL intensities around PA, we proposed two intervals of buffers (i.e., the first polluted and the high-intensity intervals) that can well-characterize the spatial extent of those sensitive regions. The first buffer in a specific year was defined as the nearest buffer with lit pixels. Thus, the first polluted interval (Figure 3a) was defined as between the furthest (e.g., the 30th buffer in 1992) and the nearest (e.g., the buffer in 2018) during the whole period. This interval reflects the NTL impact on PAs from a spatial distance, and those PAs having closer buffers with lit pixels are easier to be affected by the light pollution. Differently, we also defined the interval using the intensity of NTL (Equation (1)), in which both the DN values of lit pixels and their distances to PAs were considered (Figure 3b). Similarly, we calculated the minimum (e.g., the 50th buffer in 1992) and maximum (e.g., the 20th buffer in 2018) buffers from 1992 
to 2018 and defined their interval as the high-intensity interval (e.g., the 20th to 50th buffer in Figure 3b).

$$
I_{i}=\frac{N T L_{\text {sum }}\left(B_{i}-B_{i-1}\right)}{B_{i}}
$$

where $I_{i}$ is the intensity of $i^{\text {th }}$ buffer, $B_{i}$ is the $i^{\text {th }}$ buffer, and NTL $L_{\text {sum }}$ is the sum of NTL in the buffer ring $i$ (i.e., $B_{i}-B_{i-1}$ ).

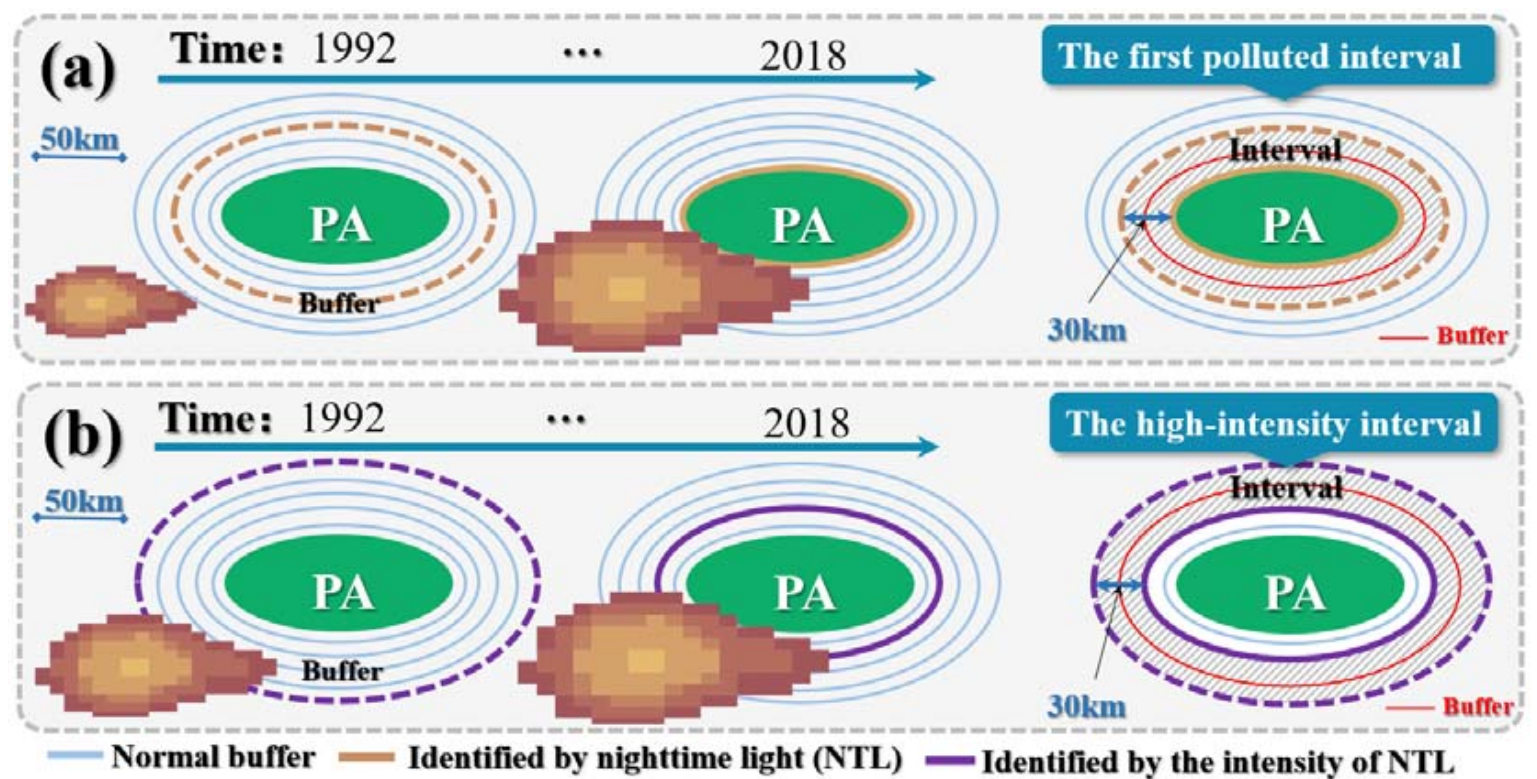

Figure 3. Conceptual illustration of buffer intervals around PA revealed by the first polluted buffer (a) and the highintensity buffer (b). Note: yellow and purple were used to indicate different pollution intervals (i.e., the first pollution and high-intensity interval).

We analyzed the temporal trend of NTL in different regions for continuously and discontinuously polluted PAs. Due to urban sprawl and human activities, PAs are likely to be affected by NTL over the past decades, i.e., the first polluted buffer becomes close to PAs with increasing intensity of NTL over the years. Therefore, for continuously polluted PAs, we analyzed the temporal trend of NTL inside the PA and the high-intensity interval because the first polluted buffer was merged with PA since 1992. However, for discontinuously polluted PAs, we investigated the temporal trend of NTL in the first polluted interval and high-intensity interval (a detailed case of the high-intensity interval can be referred to Seattle in Figure S3).

\section{Results}

\subsection{Spatially Explicit Distribution of Light Pollution Categories}

Those PAs in Europe, the USA, and East Asia have had more severe light pollution than other regions over the past decades (Figure 4). Globally, numbers of PAs defined as non-polluted, continuously polluted, and discontinuously polluted are 24,650, 8141, and 16,509, respectively (Figure $4 \mathrm{a}$ ), suggesting that almost $50 \%$ of global PAs have been affected by NTL. To better visualize their distributions, we generated kernel density maps using the centroid of PA with different light pollution categories and then composited them at different channels (Figure 4b). Most light pollution was observed in regions with latitudes from $30^{\circ} \mathrm{N}$ to $60^{\circ} \mathrm{N}$, exhibiting three critical regions of Europe, the USA, and East Asia. The continuously polluted PAs (red color in Figure 4b) are widely distributed in Europe, suggesting these PAs have been affected by NTLs since the 1990s. This is largely due to the relatively close distance between PAs and cities in Europe. The numbers of continuously and discontinuously polluted PAs are 4096 and 4601, respectively, with a total 
area of 1.69 million $\mathrm{km}^{2}$. There is a distinct separation of continuously polluted (i.e., east) and discontinuously polluted (i.e., west) PAs in the USA. The total area of polluted PAs in the USA is 0.95 million $\mathrm{km}^{2}$, and the areas of 1674 continuously and 4028 discontinuously polluted areas are 0.3 and 0.65 million $\mathrm{km}^{2}$, respectively.
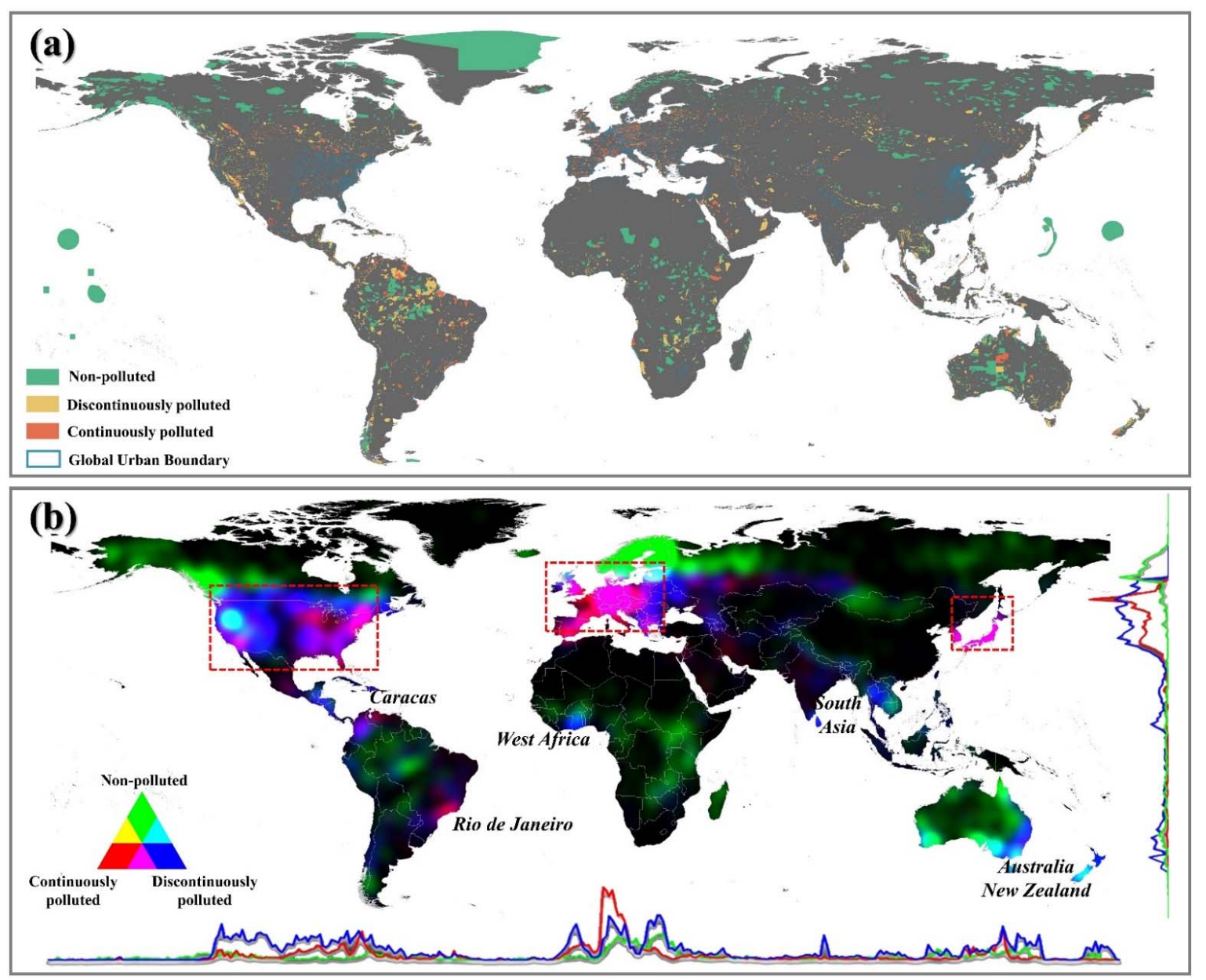

Figure 4. Spatial distribution of different light pollution categories (a) and their composited visualization using continuously polluted (R), non-polluted (G), and discontinuously polluted (B) (b).

The widely distributed discontinuously polluted PAs indicate that urbanization with increased NTL use has posed noticeable challenges to the protection of PAs. For example, there are many global urban clusters greater than $100 \mathrm{~km}^{2}$ in the USA [54]. The category of continuously polluted is the dominant type of light pollution in East Asia, particularly in South Korea and Japan. It is worth noting that the WDPA contains limited PAs in China, making it challenging to evaluate China's light pollution. Moreover, five hotspots deserve attention worldwide, including Caracas (the capital of Venezuela) and Rio de Janeiro (Brazil) in South America, West Africa, South Asia, and Australia (Figure 4b). The urbanization of South America began in the early years and the deforestation mainly occurred in Amazon [55], which caused many continuously polluted PAs during the whole period. Besides, with rapid urbanization [56], the PAs with non-polluted were gradually translated to discontinuously polluted, and most of them are located in West Africa, South Asia, and Australia.

\subsection{Temporal Trends of NTL in Different Light Pollution Categories}

There is an increasing temporal trend in polluted PA worldwide over the past decades, especially in Europe and South America (Figure 5). The continuously polluted PAs in 
Europe account for $51 \%$ of the world, dominated by increasing NTL (Figure 5a). Among these PAs, $24 \%$ of them show a significant increased trend with $p$-values below 0.05 . Most of the discontinuously polluted PAs with a significant increase are distributed in South America, West Africa, India, and South Asia (Figure 5b) (Table 1). For example, the proportion of PAs with a significant increase in South America is larger than $50 \%$, suggesting a notable growth of NTL luminance. The difference between Europe and South America in different pollution categories indicates the rapid growth of city light in South America's developing areas due to urban sprawl. At the continental scale, the polluted PAs (i.e., continuously and discontinuously polluted) show a distinct spatial heterogeneity (Figure 5), especially in South America, West Africa, South Asia, and Oceania. The dominant trend of NTL change in South America is increasing in continuously and discontinuously polluted PAs, suggesting a considerable intervention of human activities related to the NTL luminance (e.g., urban sprawl). The discontinuously polluted PAs in Africa show an increasing trend (accounting for 50\%), especially in West Africa.
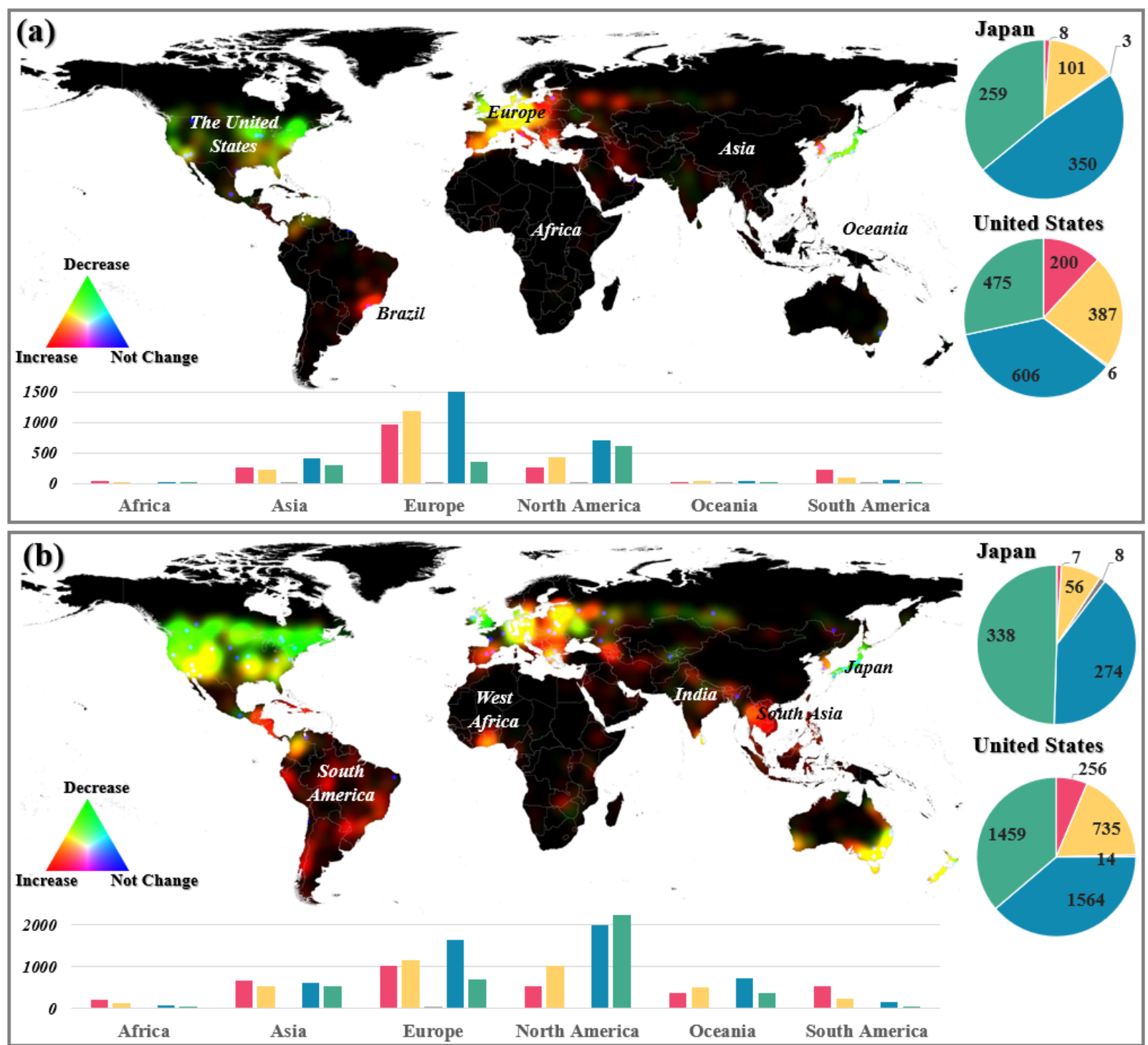

Significant increase $\square$ Insignificant increase $\square$ No change $\square$ Insignificant decrease $\square$ Significant decrease

Figure 5. The temporal trends of NTL worldwide in continuously polluted (a) and discontinuously polluted (b) PAs. The visualization of kernel density maps is composited by channels of increase (R), decrease (G), and no change (B). Note: the search radius of the kernel density is 5 degrees, and the weight is the natural logarithm of the area. 
Table 1. The percentage of PAs with different significance levels of the temporal trends of NTL in continuously and discontinuously polluted protected areas.

\begin{tabular}{|c|c|c|c|c|c|c|c|c|c|c|c|c|}
\hline & \multicolumn{6}{|c|}{ Continuously Polluted PAs } & \multicolumn{6}{|c|}{ Discontinuously Polluted PAs } \\
\hline & $\begin{array}{c}\text { SI } \\
(\%)\end{array}$ & $\begin{array}{c}\text { II } \\
(\%)\end{array}$ & $\begin{array}{l}\text { NC } \\
(\%)\end{array}$ & $\begin{array}{l}\text { ID } \\
(\%)\end{array}$ & $\begin{array}{l}\text { SD } \\
(\%)\end{array}$ & Sum & $\begin{array}{c}\text { SI } \\
(\%)\end{array}$ & $\begin{array}{c}\text { II } \\
(\%)\end{array}$ & $\begin{array}{l}\text { NC } \\
(\%)\end{array}$ & $\begin{array}{l}\text { ID } \\
(\%)\end{array}$ & $\begin{array}{l}\text { SD } \\
(\%)\end{array}$ & Sum \\
\hline Japan & 1.11 & 14.01 & 0.42 & 48.54 & 35.92 & 721 & 1.02 & 8.20 & 1.17 & 40.12 & 49.49 & 683 \\
\hline United Stated & 11.95 & 23.12 & 0.36 & 36.20 & 28.38 & 1674 & 6.36 & 18.25 & 0.35 & 38.83 & 36.22 & 4028 \\
\hline Africa & 53.85 & 26.92 & 0.00 & 11.54 & 7.69 & 78 & 45.95 & 27.44 & 0.00 & 17.46 & 9.15 & 481 \\
\hline Asia & 20.95 & 18.91 & 0.49 & 34.39 & 25.26 & 1227 & 28.07 & 22.47 & 0.67 & 26.23 & 22.56 & 2394 \\
\hline Europe & 23.73 & 29.13 & 0.39 & 38.16 & 8.59 & 4096 & 22.36 & 25.43 & 1.00 & 35.73 & 15.47 & 4601 \\
\hline North American & 13.27 & 21.58 & 0.39 & 34.56 & 30.19 & 2034 & 9.12 & 17.60 & 0.33 & 34.19 & 38.75 & 5811 \\
\hline Oceania & 23.73 & 29.66 & 0.85 & 28.81 & 16.95 & 118 & 18.33 & 26.09 & 0.90 & 36.10 & 18.58 & 1997 \\
\hline South American & 53.30 & 24.53 & 0.47 & 14.39 & 7.31 & 424 & 54.56 & 23.77 & 0.30 & 15.85 & 5.52 & 997 \\
\hline Global & 22.43 & 25.35 & 0.42 & 34.91 & 16.89 & 8141 & 41.55 & 18.40 & 0.23 & 21.93 & 17.90 & 16,509 \\
\hline
\end{tabular}

Note: Significant increase (SI), insignificant increase (II), no change (NC), insignificant decrease (ID), significant decrease (SD).

Global polluted PAs with a decreasing temporal trend are mainly distributed in the USA and Japan, and such a pattern is consistent in both the continuously and discontinuously polluted categories (Figure 5). The proportion of polluted PAs with a decreasing trend in Japan is about $85 \%$, of which $35 \%$ of PAs are statistically significant. The proportion of discontinuously polluted PAs with a decreasing trend reaches $90 \%$ in Japan, and around $50 \%$ of these PAs pass the significance test. This phenomenon is mainly attributed to the well-planned conservation policies of light pollution in these two regions. For example, Japan is the first country to develop guidelines for mitigating the effect of light pollution [57]. The continuously polluted PAs with decreasing trends are mainly $(\sim 65 \%)$ distributed in the Great Lakes region of the USA. The discontinuously polluted PAs in the USA are also dominated $(75 \%)$ by a decreasing trend. This phenomenon is related to the phase of urbanization and population loss; e.g., there is a noticeable outflow of the population in the Great Lakes region [58].

\subsection{The Distance of Light Pollution to the Protected Areas}

Globally, most polluted PAs are close (i.e., less than $10 \mathrm{~km}$ ) to the first polluted buffer and the high-intensity buffer (Table 2). Here, the averaged first polluted buffer and the high-intensity buffer were defined as their averages in different years. Then, we divided these PAs into three categories according to the distribution of the averaged first polluted buffer and the high-intensity buffer of all polluted PAs. We found most PAs with the averaged first polluted buffer of less than $10 \mathrm{~km}$ are in Europe, the USA, South America, and Asia (Figure 6a). In the USA, there is a noticeable spatial heterogeneity of the distance of light pollution to the PAs; i.e., PAs in the east of the USA are more likely to be affected due to the widely distributed cities. According to the global urban boundaries [54], cities with over $100 \mathrm{~km}^{2}$ in the USA are mainly distributed in the east. The averaged first polluted buffer of PAs in East Asia (e.g., Japan) is closer (less than $10 \mathrm{~km}$ ) than those in South Asia (e.g., India) $(10 \mathrm{~km} \sim 25 \mathrm{~km})$. While in South America, the first polluted buffer of most PAs in the Amazon rainforest is above $25 \mathrm{~km}$. The PAs that are far from NTL (beyond $25 \mathrm{~km}$ ) are mainly distributed in Australia, New Zealand, and the west USA. Additionally, PA types need attention due to their functions (Table 2). For example, PA types of IV (habitat/species management area) and V (protected landscape/seascape) account for $64 \%$ of all PAs, with the averaged first polluted buffer less than $10 \mathrm{~km}$. The light pollution is limited to PAs with Ia (strict nature reserve) due to its high priority of conservation. Those PAs close (less than $10 \mathrm{~km}$ ) to the averaged high-intensity polluted buffer are mainly in Europe and Brazil (Figure 6b), accounting for 38\% of the global polluted PA. Compared to the first polluted buffer, the high-intensity interval represents more substantial impacts of human activity on PAs. Similarly, most (76\%) of these PAs belong to the IV (habitat/species management area) 
and V (protected landscape/seascape), suggesting these types are more easily affected by human activities.

Table 2. Number and types of polluted PAs with different distances to the averaged first and high-intensity polluted buffer.

\begin{tabular}{|c|c|c|c|c|c|c|c|c|}
\hline \multirow[b]{2}{*}{ Type } & \multicolumn{4}{|c|}{ The First Polluted Buffer (km) } & \multicolumn{4}{|c|}{ The High-Intensity Buffer (km) } \\
\hline & Buffer $\leq 10$ & $10<$ Buffer $<25$ & Buffer $\geq 25$ & Sum & Buffer $\leq \mathbf{1 0}$ & $10<$ Buffer $<25$ & Buffer $\geq 25$ & Sum \\
\hline $\mathrm{Ia}$ & $521(44 \%)$ & $427(36 \%)$ & $229(20 \%)$ & 1177 & $226(17 \%)$ & $342(27 \%)$ & $719(56 \%)$ & 1287 \\
\hline $\mathrm{Ib}$ & $817(57 \%)$ & $434(31 \%)$ & $174(12 \%)$ & 1425 & $273(17 \%)$ & $418(27 \%)$ & $889(56 \%)$ & 1580 \\
\hline II & $1329(57 \%)$ & $707(31 \%)$ & $270(12 \%)$ & 2306 & $903(32 \%)$ & $759(26 \%)$ & $1196(42 \%)$ & 2858 \\
\hline III & $502(44 \%)$ & $397(34 \%)$ & $248(22 \%)$ & 1147 & $297(22 \%)$ & $347(26 \%)$ & $696(52 \%)$ & 1340 \\
\hline IV & $3801(74 \%)$ & $1113(21 \%)$ & $239(5 \%)$ & 5153 & $2912(38 \%)$ & $1796(23 \%)$ & $3013(39 \%)$ & 7721 \\
\hline $\mathrm{V}$ & $3195(80 \%)$ & $656(16 \%)$ & $173(4 \%)$ & 4024 & $4231(65 \%)$ & $1616(25 \%)$ & $668(10 \%)$ & 6515 \\
\hline VI & $696(55 \%)$ & $461(36 \%)$ & $120(9 \%)$ & 1277 & $515(15 \%)$ & $462(14 \%)$ & $2372(71 \%)$ & 3349 \\
\hline Sum & $10,861(66 \%)$ & 4195 (25\%) & $1453(9 \%)$ & 16,509 & $9357(38 \%)$ & $5740(23 \%)$ & $9553(39 \%)$ & 24,650 \\
\hline
\end{tabular}

Note: strict nature reserve (Ia), wilderness area (Ib), national park (II), natural monument of feature (III), habitat/species management area (IV), protected landscape/seascape (V), protected area with sustainable use of natural resources (VI). The averaged first polluted buffer is defined as the average of the first polluted buffers during 1992 to 2018, as does the high-intensity buffer.
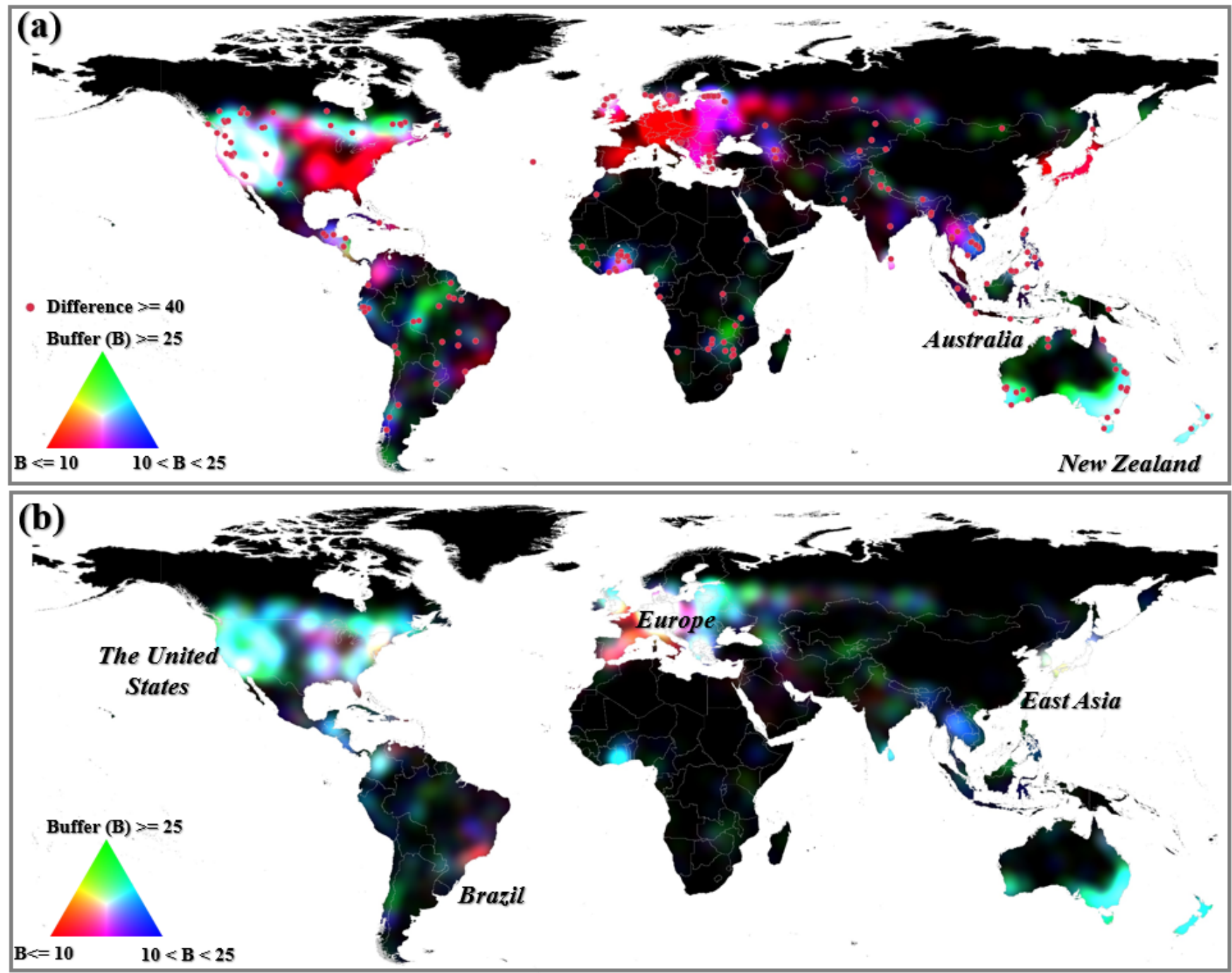

Figure 6. The distance of PAs to the averaged first (a) and high-intensity (b) polluted buffers. The visualization of maps is composited by channels of distance to buffers (buffer $<=10, \mathrm{R} ; 10<$ buffer $<25$, G; buffer $>=25$, B). Those red points with distances beyond $40 \mathrm{~km}$ are mainly caused by unstable light sources (e.g., ports, logging, and shipping). 


\subsection{The Temporal Trends of NTL in High-Intensity Intervals}

Hotspots of global PAs can be revealed from their spatial maps and temporal trends of light pollution in high-intensity intervals, while showing that the continuously polluted PAs are highly correlated with urbanization (Figure 7). Spatially, PAs with a high value of NTL in the high-intensity polluted intervals from 1992 to 2018 are mainly distributed in the USA, Europe, East Asia, Venezuela, and Brazil (Figure 7a). However, when regarding their temporal trends of NTL over the past decades, the USA and Japan have decreasing NTL (Figure $7 \mathrm{~b}$ ). Meanwhile, we found that the temporal trends of light pollution are increasing in the Middle East, Indian, and South Asia. In the USA, the temporal trends of NTL in polluted PAs translated from decreasing in the north to increasing in the south (Figure 7c). The main polluted category in Europe is continuously polluted (Figure 7d). The temporal trend of NTL is increasing, except northern Europe, where the population has been slightly decreasing over the past decades [59]. In Japan, the continuously polluted PAs are close to the urban, whereas the time trend decreases (Figure 7e). This phenomenon mainly contributes to well-planned ecological conservation policies; e.g., Japan is the first country to develop guidelines for light pollution [57]. The trend of light pollution in South America is increasing, especially in Venezuela (Figure 7f) and Brazil (Figure 7g). What these places have in common is that continuously polluted PAs are near urban areas larger than $100 \mathrm{~km}^{2}$.
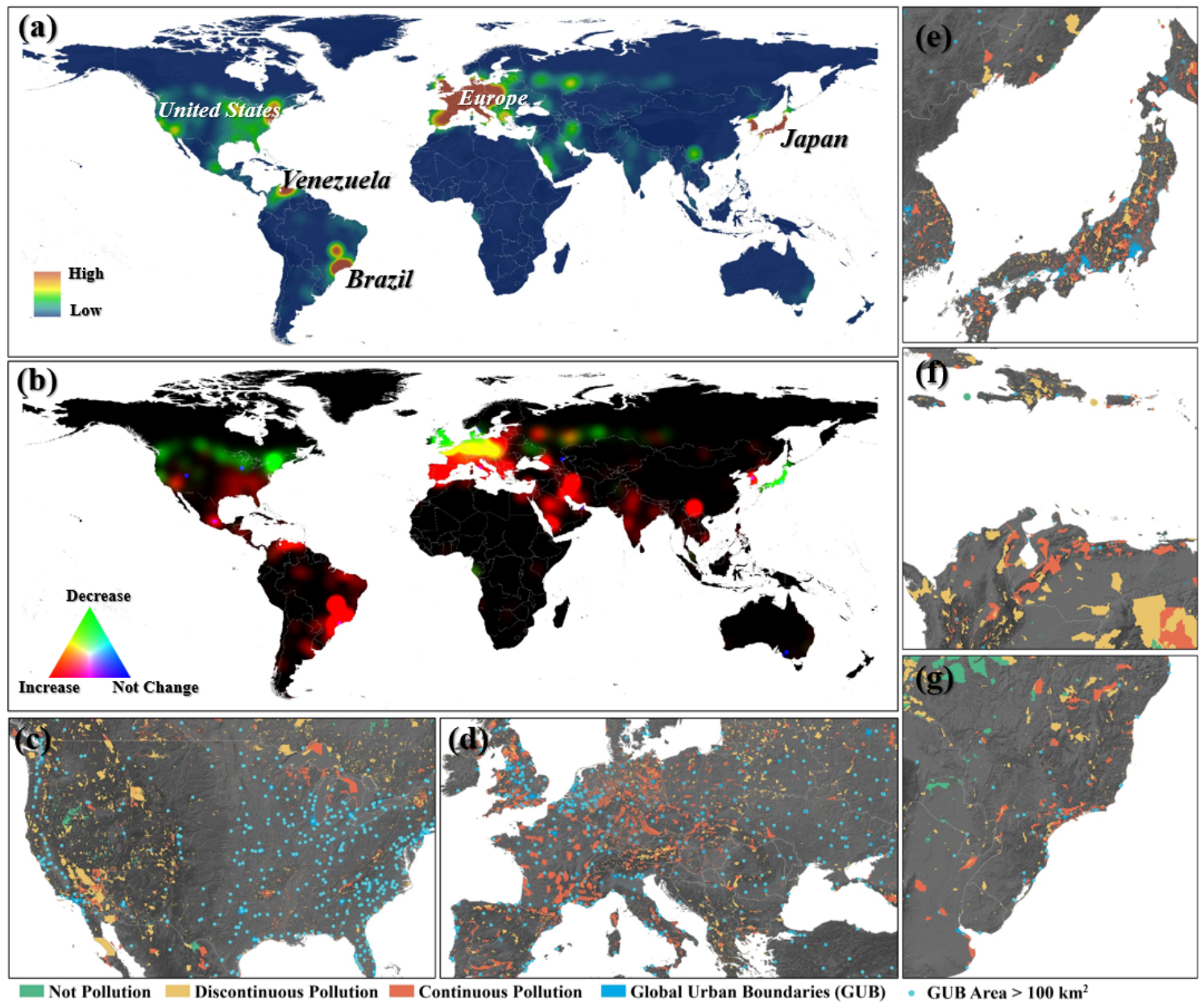

Figure 7. Distribution of global polluted PAs with high value of NTL in the high-intensity interval (a) and their temporal trends of NTL over the past decades (b). Detailed cases in (c-g) in (a) can be found in enlarged views. Note: the mean value of NTL and temporal trend of annual NTL sum in the high-intensity interval were visualized by the kernel density approach to identify these five global hotspots. 


\section{Discussion}

\subsection{The Influence of Policies on Light Pollution}

The dominant decreasing trend of NTL in PAs in Japan and the USA is closely related to protection policies and organizations. The first governmental guideline about light pollution was published in March 1998 in Japan [57]. The Ministry of Environment in Japan has published light pollution control guidelines to help local authorities take efficient control measures and enforce special environmental regulations. For instance, the Okayama prefecture enacted the first regulation in Japan to deal with light pollution to protect spacebased radio astronomy observations in 1989. Moreover, in the USA, some organizations have been founded to mitigate the negative impacts of light pollution [60], such as the New England Light Pollution Advisory Group (NELPAG), the International Dark-Sky Association (IDA), and the Dark Skies Advisory Group (DSAG) [61]. With years of hard work, the status of light pollution in Japan and the USA has been mitigated considerably, which is helpful to realize the sustainable development of ecology and environment in/around urban domains.

\subsection{The Ecological Impact of Light Pollution}

Many studies have demonstrated that light pollution could impact wildlife on foraging, reproduction, migration, and communication in natural systems. Artificial light can extend the period of foraging behavior of animals, which could introduce disturbances in the ecosystem and communities [1]. Additionally, artificial light may confuse organisms accustomed to navigating in a dark environment [62]. The sea turtles hatched from nests would be disorientated by nighttime light, which would affect their reproduction [63]. Birds can be disoriented and collided with others by lights at night [64]. Many insects, such as moths, are likely to be attracted by nighttime light [18].

Compared to continuously polluted PAs, the short-term nighttime lights revealed from the discontinuously polluted PA (e.g., near Zhangjiajie in Figure S2) have a greater impact on the ecosystem, e.g., the wild animals need to adapt to such emerging nighttime lights. This is also an important reason for humans to prevent light pollution from spreading to PA. To identify the sprawl of light pollution in the future, we provided early warning of global light pollution for biodiversity and wildlife by mapping the light pollution source (i.e., the first polluted buffer and the high-intensity buffer) and their distances to PAs. These new insights into light pollution are not available in previous studies $[14,36]$.

Light pollution continues to expand on Earth. However, for many species and ecosystems, its impacts have not been examined on a global scale. Human pressures on the natural system, commonly referred to as threats to biodiversity, are from diverse human activities [65], such as built environment, road, pasture, and nighttime light, etc. Especially, the impact of nighttime light on wildlife is complex, which can change the habits of some species (e.g., owl, insects, and migratory birds, etc.). Specially, the International Union for Conservation of Nature (IUCN) Red List will be employed to explore the impact of light pollution on threatened species on a continental scale in the future. This is helpful for biodiversity conservation, i.e., the INCU Red List was widely used to evaluate the vulnerability of PA in the face of climate, human footprint, and agricultural expansion [66,67].

Additionally, blue light is a new emerging source of light pollution due to the increased use of LED lighting $[60,68]$. Unfortunately, such kinds of lights cannot be well-detected by DMSP/OLI and VIIRS/NDB [69], and its impact was not considered in our study. Some new remote sensing platforms have recently been used to monitor blue light pollution using advanced sensors [69] and new indices [70], which will be considered in future works of global light pollution.

\subsection{The Relationship between Light Pollution and Urbanization}

Only $26 \%$ of 24,650 polluted PAs were found to have significantly decreasing trends, whereas $56 \%$ of them were found to have increasing trends, and these results are related to the rapid urbanization. We found that the areas of polluted PAs with the increasing 
temporal trend are relatively large. The continental polluted PAs $\left(9.90\right.$ million $\left.\mathrm{km}^{2}\right)$ with increasing trends (56\%) account for at least 6.58 million $\mathrm{km}^{2}$ in extent. Here, we used the global artificial impervious area (GAIA) [71] to study potential implications for the planet's urbanization and biodiversity conservation (Table 3). We found the ratios of PA with the increasing trend are consistent with the increasing rates of impervious surface area (ISA) (Figure 8). The increasing rates of ISA from 1992 to 2018 in Africa and Oceania are approaching $200 \%$, but the ratios of PAs with the increasing trend are significantly different (e.g., $74 \%$ in Africa and $45 \%$ in Oceania). This indicates a lack of attention to light pollution in PAs during the urbanization process in Africa and South America. Japan handled the conflict between urbanization and conservation of PA well, illustrating the importance of positive protection policies. Moreover, given that the rapid global urbanization in China $[72,73]$ and the overall trends (Figure 8), PAs will be facing a great threat of light pollution in the near future.

Table 3. Statistics of polluted PAs and impervious surface area across different regions.

\begin{tabular}{|c|c|c|c|c|c|c|}
\hline & \multicolumn{3}{|c|}{ The Polluted Protected Areas } & \multicolumn{3}{|c|}{ Impervious Surface Area } \\
\hline & Increasing & Decreasing & Total & $1992\left(\mathrm{~km}^{2}\right)$ & $2018\left(\mathrm{~km}^{2}\right)$ & $\begin{array}{c}\text { Increasing } \\
\text { Rate }\end{array}$ \\
\hline Japan & $172(12 \%)$ & 1221 & 1404 & 19972 & 29402 & $147.21 \%$ \\
\hline United Sated & $1578(28 \%)$ & 4104 & 5702 & 162,000 & 272,000 & $167.90 \%$ \\
\hline Africa & $416(74 \%)$ & 143 & 559 & 27,913 & 55,665 & $199.42 \%$ \\
\hline Asia & $1699(47 \%)$ & 1900 & 3621 & 169,000 & 474,000 & $280.47 \%$ \\
\hline Europe & $4364(50 \%)$ & 4271 & 8697 & 127,000 & 260,000 & $204.72 \%$ \\
\hline North American & $2262(29 \%)$ & 5556 & 7845 & 185,000 & 320,000 & $172.97 \%$ \\
\hline Oceania & $950(45 \%)$ & 1146 & 2115 & 7927 & 15,637 & $197.27 \%$ \\
\hline South American & $1111(78 \%)$ & 305 & 1421 & 20,622 & 51,091 & $247.75 \%$ \\
\hline Global & $13,786(56 \%)$ & 10,792 & 24,650 & 537,461 & $1,176,393$ & $218.88 \%$ \\
\hline
\end{tabular}

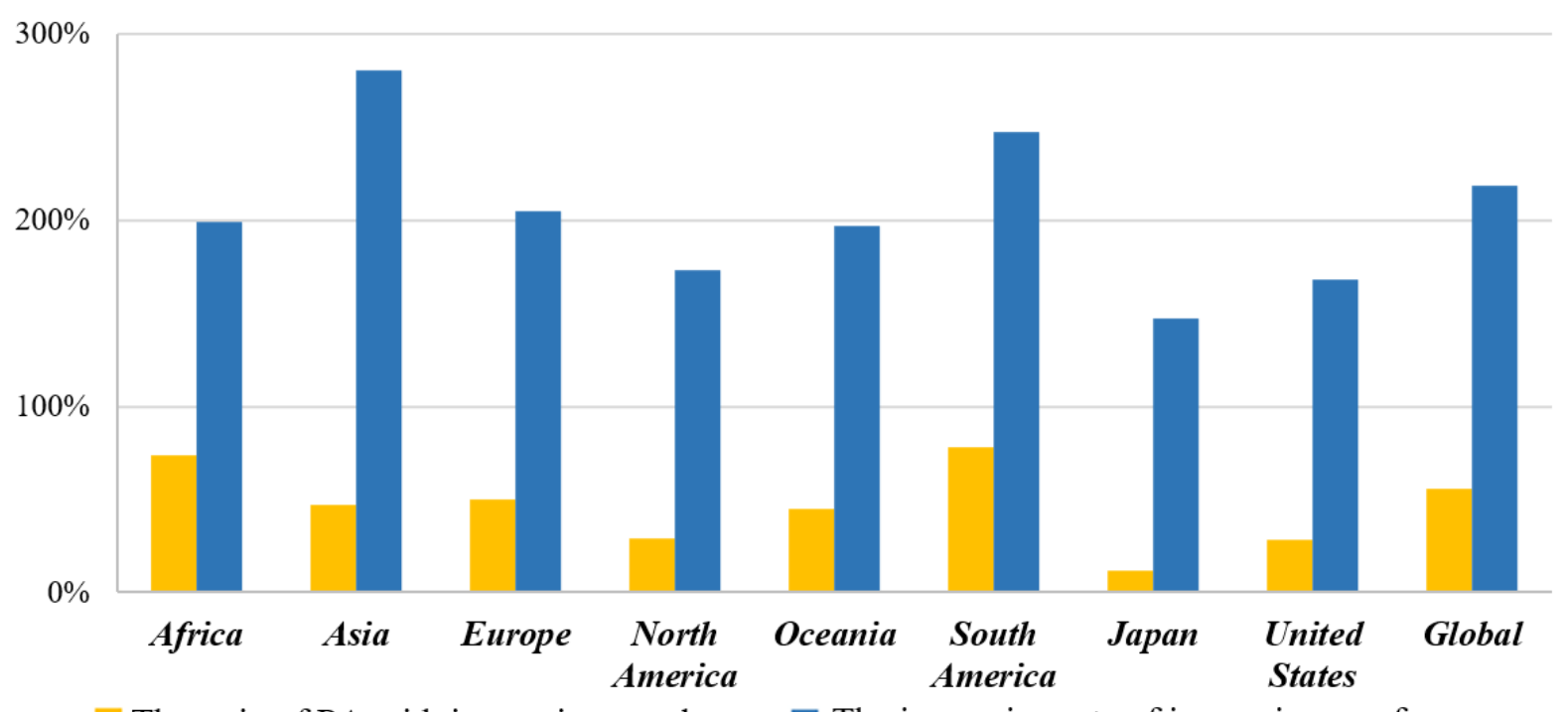

The ratio of PA with increasing trend

The increasing rate of impervious surface area

Figure 8. The relationship between light pollution (i.e., the ratio of polluted PA with an increasing trend) and urbanization (i.e., the increasing rate of impervious surface areas).

\subsection{Uncertainty}

Here, we discussed the uncertainty of the evaluation of light pollution using the harmonized global NTL dataset [2]. The uncertainty of this dataset mainly lies in two aspects, including the employed data and model. On the one hand, the DMSP and VIIRS NTL, as two different kinds of data, have different observation records (i.e., digital number and radiation), transit time (i.e., 9:00 pm and 1:30 am), and spatial resolution (i.e., 30-arc and 15 -arc). On the other hand, a sigmoid function was employed to convert VIIRS radiance 
data to the DMSP-like data. When the DMSP-like digital number values from VIIRS are low, the uncertainly of the model is relatively large. Therefore, a technical validation was performed, and it was discovered that excluding low luminance regions using the threshold of 7, the derived NTL result from VIIRS is closer to the DMSP data [2]. Some nighttime light with DN values less than 7 in small towns and settlements might be neglected in our study. Overall, the approach in this dataset outperforms other approaches in terms of temporal consistency. For example, we compared the results with other studies on global light pollution [23]; a similar temporal trend distribution appeared (e.g., the east of the USA and Japan have a clear decline trend in NTL from the DMSP).

There are additional limitations between satellite-based global light pollution evaluation and ground light pollution measurement. First, the outdoor lighting facilities and technologies rapidly change in the spectrum, direction, and total flux of lamps [60]. As a result, the night sky will change, and the traditional NTL observations such as DMSP/OLI and VIIRS/DNB may fail to detect new light sources such as blue light. Second, due to the viewing angle, polarization, and wavelength, the ground light pollution cannot be directly observed by satellites $[38,69]$. Future satellite mega-constellations are expected to significantly increase light pollution [74], which brings great uncertainly to future research on light pollution.

\section{Conclusions}

In this study, we developed a framework to evaluate the light pollution in global PAs using WDPA and globally harmonized NTL data over the past decades (1992 to 2018). We identified three categories of light pollution (i.e., 5974 non-polluted, 8141 continuously polluted, and 16,509 discontinuously polluted) in PA and investigated the global distribution of these PAs. Then, we analyzed the temporal trend of NTL in polluted (i.e., the continuously and discontinuously polluted) PAs. Specifically, NTL trends in the first polluted interval and high-intensity intervals were analyzed with consideration of protection policies and urbanization.

Those PAs affected by NTL are mainly distributed in regions with latitudes from $30^{\circ} \mathrm{N}$ to $60^{\circ} \mathrm{N}$, representing three key regions (i.e., Europe, the USA, and East Asia). Overall, because of global urbanization, the temporal trend of NTL in global PAs is increasing, except for the USA and Japan, showing a slightly decreasing trend. This is probably related to socioeconomic and demographic factors. Most PAs are close to lit pixels when regarding their distances to the first or the high-intensity polluted buffers (i.e., less than $10 \mathrm{~km}$ ), especially for the PA types of habitat/species management area (IV) and protected landscape/seascape (V). These PAs are more likely to be affected by light pollution than other regions under future global urbanization scenarios.

Characterizing the spatial relationship between PAs and NTL and the trend of NTL intensity in/around PAs is of high importance for biodiversity conservation. Our study provides a global perspective on light pollution in worldwide PAs and identified different types and hotspots of PAs using temporally consistent NTL time series data. Global urbanization is the main driver raising the risk of light pollution in/around PAs, of which their distance to NTL has become close over the past decades. As a result, more attention is required to mitigate these risks to support sustainable development. It is also worthy to note that the number of PAs in China is not so many in WDPA, although China has experienced prevalent urban sprawl over the past decades [72].

Supplementary Materials: The following are available online at https: / www.mdpi.com/article/10 $.3390 /$ rs13091849/s1. Figure S1: An illustration of continuously polluted category. The case area in Paris (France) (a) and change of nightlights (b). Figure. S2: An illustration of the discontinuously polluted category in Zhangjiajie (China) (a) with NTL dynamics (b) and temporal trend analysis (c). Figure. S3: An illustration of buffers around the protected area in Seattle and the highlighted high-intensity intervals. 
Author Contributions: Conceptualization, X.L.; methodology, X.L., and H.M.; software, H.M., Y.W.; validation, X.L., and H.M.; formal analysis, X.L., and H.M.; investigation, H.M.; resources, X.L., X.D., J.H. and W.S.; data curation, X.L.; writing—original draft preparation, H.M.; writing-review and editing, X.L., H.M., Y.W., Y.H., J.H., W.S., T.H., P.Y., F.X., and X.D.; visualization, H.M.; supervision, X.L., J.H., and W.S.; project administration, X.L.; funding acquisition, X.L. All authors have read and agreed to the published version of the manuscript.

Funding: This research was funded by the Chinese University Scientific Fund, grant number 15051001.

Data Availability Statement: The data presented in this study are available on request from the corresponding author.

Acknowledgments: We acknowledge the protected planet program for their share of the WDPA dataset. We thank the editors and reviewers for their helpful and constructive comments on our work.

Conflicts of Interest: The authors declare no conflict of interest.

\section{References}

1. $\quad$ Longcore, T.; Rich, C. Ecological light pollution. Front. Ecol. Environ. 2004, 2, 191-198. [CrossRef]

2. Li, X.; Zhou, Y.; Zhao, M.; Zhao, X. A harmonized global nighttime light dataset 1992-2018. Sci. Data 2020, 7, 1-9. [CrossRef]

3. Li, X.; Zhou, Y.; Eom, J.; Yu, S.; Asrar, G.R. Projecting global urban area growth through 2100 based on historical time series data and future Shared Socioeconomic Pathways. Earth's Future 2019, 7, 351-362. [CrossRef]

4. Li, X.; Zhou, Y.; Zhu, Z.; Cao, W. A national dataset of $30 \mathrm{~m}$ annual urban extent dynamics (1985-2015) in the conterminous United States. Earth Syst. Sci. Data 2020, 12, 357-371. [CrossRef]

5. Gaston, K.J.; Bennie, J.; Davies, T.W.; Hopkins, J. The ecological impacts of nighttime light pollution: A mechanistic appraisal. Biol. Rev. 2013, 88, 912-927. [CrossRef] [PubMed]

6. Schulze, K.; Knights, K.; Coad, L.; Geldmann, J.; Leverington, F.; Eassom, A.; Marr, M.; Butchart, S.H.; Hockings, M.; Burgess, N.D. An assessment of threats to terrestrial protected areas. Conserv. Lett. 2018, 11, e12435. [CrossRef]

7. Visconti, P.; Butchart, S.H.; Brooks, T.M.; Langhammer, P.F.; Marnewick, D.; Vergara, S.; Yanosky, A.; Watson, J.E. Protected area targets post-2020. Science 2019, 364, 239-241. [CrossRef] [PubMed]

8. Zhilin, L.; Gong, X.; Chen, J.; Mills, J.; Songnian, L.; Zhu, X.; Peng, T.; Hao, W. Functional requirements of systems for visualization of Sustainable Development Goal (SDG) indicators. J. Geovisualization Spat. Anal. 2020, 4, 1-10. [CrossRef]

9. Guo, H. Big Earth Data in Support of the Sustainable Development Goals (2019); Secience Press: Beijing, China, 2019.

10. Xu, W.; Pimm, S.L.; Du, A.; Su, Y.; Fan, X.; An, L.; Liu, J.; Ouyang, Z. Transforming protected area management in China. Trends Ecol. Evol. 2019, 34, 762-766. [CrossRef] [PubMed]

11. Hannah, L.; Midgley, G.; Andelman, S.; Araújo, M.; Hughes, G.; Martinez-Meyer, E.; Pearson, R.; Williams, P. Protected area needs in a changing climate. Front. Ecol. Environ. 2007, 5, 131-138. [CrossRef]

12. Hölker, F.; Wolter, C.; Perkin, E.K.; Tockner, K. Light pollution as a biodiversity threat. Trends Ecol. Evol. 2010, 25, 681-682. [CrossRef]

13. Davies, T.W.; Smyth, T. Why artificial light at night should be a focus for global change research in the 21st century. Glob. Chang. Biol. 2018, 24, 872-882. [CrossRef] [PubMed]

14. Bennie, J.; Duffy, J.P.; Davies, T.W.; Correa-Cano, M.E.; Gaston, K.J. Global trends in exposure to light pollution in natural terrestrial ecosystems. Remote Sens. 2015, 7, 2715-2730. [CrossRef]

15. Seymoure, B.; Buxton, R.; White, J.; Linares, C.; Fristrup, K.; Crooks, K.; Wittemyer, G.; Angeloni, L. Anthropogenic light disrupts natural light cycles in critical conservation areas. SSRN 2019. [CrossRef]

16. Gaston, K.J.; Davies, T.W.; Bennie, J.; Hopkins, J. Reducing the ecological consequences of night-time light pollution: Options and developments. J. Appl. Ecol. 2012, 49, 1256-1266. [CrossRef]

17. Owens, A.C.; Cochard, P.; Durrant, J.; Farnworth, B.; Perkin, E.K.; Seymoure, B. Light pollution is a driver of insect declines. Biol. Conserv. 2020, 241, 108259. [CrossRef]

18. Owens, A.C.; Lewis, S.M. The impact of artificial light at night on nocturnal insects: A review and synthesis. Ecol. Evol. 2018, 8 , 11337-11358. [CrossRef]

19. Lewanzik, D.; Voigt, C.C. Artificial light puts ecosystem services of frugivorous bats at risk. J. Appl. Ecol. 2014, 51, 388-394. [CrossRef]

20. Giavi, S.; Blösch, S.; Schuster, G.; Knop, E. Artificial light at night can modify ecosystem functioning beyond the lit area. Sci. Rep. 2020, 10, 1-11. [CrossRef] [PubMed]

21. Bennie, J.; Davies, T.W.; Cruse, D.; Gaston, K.J. Ecological effects of artificial light at night on wild plants. J. Ecol. 2016, 104, 611-620. [CrossRef]

22. Knop, E.; Zoller, L.; Ryser, R.; Gerpe, C.; Hörler, M.; Fontaine, C. Artificial light at night as a new threat to pollination. Nature 2017, 548, 206-209. [CrossRef] 
23. Guetté, A.; Godet, L.; Juigner, M.; Robin, M. Worldwide increase in Artificial Light At Night around protected areas and within biodiversity hotspots. Biol. Conserv. 2018, 223, 97-103. [CrossRef]

24. Li, X.; Zhou, Y.; Zhu, Z.; Liang, L.; Yu, B.; Cao, W. Mapping annual urban dynamics (1985-2015) using time series of Landsat data. Remote Sens. Environ. 2018, 216, 674-683. [CrossRef]

25. Zhou, Y.; Li, X.; Asrar, G.R.; Smith, S.J.; Imhoff, M. A global record of annual urban dynamics (1992-2013) from nighttime lights. Remote Sens. Environ. 2018, 219, 206-220. [CrossRef]

26. Zhao, M.; Zhou, Y.; Li, X.; Cao, W.; He, C.; Yu, B.; Li, X.; Elvidge, C.D.; Cheng, W.; Zhou, C. Applications of satellite remote sensing of nighttime light observations: Advances, challenges, and perspectives. Remote Sens. 2019, 11, 1971. [CrossRef]

27. Levin, N.; Kyba, C.C.; Zhang, Q.; de Miguel, A.S.; Román, M.O.; Li, X.; Portnov, B.A.; Molthan, A.L.; Jechow, A.; Miller, S.D. Remote sensing of night lights: A review and an outlook for the future. Remote Sens. Environ. 2020, 237, 111443. [CrossRef]

28. Li, X.; Zhou, Y. Urban mapping using DMSP/OLS stable night-time light: A review. Int. J. Remote Sens. 2017, 38, 6030-6046. [CrossRef]

29. Turner, W.; Spector, S.; Gardiner, N.; Fladeland, M.; Sterling, E.; Steininger, M. Remote sensing for biodiversity science and conservation. Trends Ecol. Evol. 2003, 18, 306-314. [CrossRef]

30. Briant, G.; Gond, V.; Laurance, S.G. Habitat fragmentation and the desiccation of forest canopies: A case study from eastern Amazonia. Biol. Conserv. 2010, 143, 2763-2769. [CrossRef]

31. Pauwels, J.; Le Viol, I.; Azam, C.; Valet, N.; Julien, J.-F.; Bas, Y.; Lemarchand, C.; de Miguel, A.S.; Kerbiriou, C. Accounting for artificial light impact on bat activity for a biodiversity-friendly urban planning. Landsc. Urban Plan. 2019, 183, 12-25. [CrossRef]

32. Gaynor, K.M.; Hojnowski, C.E.; Carter, N.H.; Brashares, J.S. The influence of human disturbance on wildlife nocturnality. Science 2018, 360, 1232-1235. [CrossRef]

33. McLaren, J.D.; Buler, J.J.; Schreckengost, T.; Smolinsky, J.A.; Boone, M.; van Loon, E.; Dawson, D.K.; Walters, E.L. Artificial light at night confounds broad-scale habitat use by migrating birds. Ecol. Lett. 2018, 21, 356-364. [CrossRef]

34. Davies, T.W.; Duffy, J.P.; Bennie, J.; Gaston, K.J. The nature, extent, and ecological implications of marine light pollution. Front. Ecol. Environ. 2014, 12, 347-355. [CrossRef]

35. Xiang, W.; Tan, M. Changes in light pollution and the causing factors in china's protected areas, 1992-2012. Remote Sens. 2017, 9, 1026. [CrossRef]

36. Fan, L.; Zhao, J.; Wang, Y.; Ren, Z.; Zhang, H.; Guo, X. Assessment of Night-Time Lighting for Global Terrestrial Protected and Wilderness Areas. Remote Sens. 2019, 11, 2699. [CrossRef]

37. Gaston, K.J.; Duffy, J.P.; Bennie, J. Quantifying the erosion of natural darkness in the global protected area system. Conserv. Biol. 2015, 29, 1132-1141. [CrossRef]

38. Horváth, G.; Kriska, G.; Malik, P.; Robertson, B. Polarized light pollution: A new kind of ecological photopollution. Front. Ecol. Environ. 2009, 7, 317-325. [CrossRef]

39. Ouyang, J.Q.; de Jong, M.; van Grunsven, R.H.; Matson, K.D.; Haussmann, M.F.; Meerlo, P.; Visser, M.E.; Spoelstra, K. Restless roosts: Light pollution affects behavior, sleep, and physiology in a free-living songbird. Glob. Chang. Biol. 2017, 23, 4987-4994. [CrossRef]

40. Davies, T.W.; Duffy, J.P.; Bennie, J.; Gaston, K.J. Stemming the tide of light pollution encroaching into marine protected areas. Conserv. Lett. 2016, 9, 164-171. [CrossRef]

41. Falchi, F.; Cinzano, P.; Elvidge, C.D.; Keith, D.M.; Haim, A. Limiting the impact of light pollution on human health, environment and stellar visibility. J. Environ. Manag. 2011, 92, 2714-2722. [CrossRef]

42. Elsen, P.R.; Monahan, W.B.; Merenlender, A.M. Reply to You et al.: The World Database on Protected Areas is an invaluable resource for global conservation assessments and planning. Proc. Natl. Acad. Sci. USA 2018, 115, E9029-E9030. [CrossRef]

43. Failler, P.; Touron-Gardic, G.; Traore, M.-S. Is Aichi Target 11 progress correctly measured for developing countries? Trends Ecol. Evol. 2019, 34, 875-879. [CrossRef] [PubMed]

44. Rodrigues, A.S.; Andelman, S.J.; Bakarr, M.I.; Boitani, L.; Brooks, T.M.; Cowling, R.M.; Fishpool, L.D.; Da Fonseca, G.A.; Gaston, K.J.; Hoffmann, M. Effectiveness of the global protected area network in representing species diversity. Nature 2004, 428, 640-643. [CrossRef] [PubMed]

45. Bingham, H.C.; Bignoli, D.J.; Lewis, E.; MacSharry, B.; Burgess, N.D.; Visconti, P.; Deguignet, M.; Misrachi, M.; Walpole, M.; Stewart, J.L. Sixty years of tracking conservation progress using the world database on protected areas. Nat. Ecol. Evol. 2019, 3, 737-743. [CrossRef] [PubMed]

46. Lewis, E.; MacSharry, B.; Juffe-Bignoli, D.; Harris, N.; Burrows, G.; Kingston, N.; Burgess, N.D. Dynamics in the global protected-area estate since 2004. Conserv. Biol. 2019, 33, 570-579. [CrossRef]

47. Li, X.; Zhou, Y. A stepwise calibration of global DMSP/OLS stable nighttime light data (1992-2013). Remote Sens. $2017,9,637$.

48. Zhao, M.; Zhou, Y.; Li, X.; Zhou, C.; Cheng, W.; Li, M.; Huang, K. Building a Series of Consistent Night-Time Light Data (1992-2018) in Southeast Asia by Integrating DMSP-OLS and NPP-VIIRS. IEEE Trans. Geosci. Remote Sens. 2019, 58, 1843-1856. [CrossRef]

49. Román, M.O.; Wang, Z.; Sun, Q.; Kalb, V.; Miller, S.D.; Molthan, A.; Schultz, L.; Bell, J.; Stokes, E.C.; Pandey, B. NASA's Black Marble nighttime lights product suite. Remote Sens. Environ. 2018, 210, 113-143. [CrossRef]

50. Fernandes, R.; Leblanc, S.G. Parametric (modified least squares) and non-parametric (Theil-Sen) linear regressions for predicting biophysical parameters in the presence of measurement errors. Remote Sens. Environ. 2005, 95, 303-316. [CrossRef] 
51. Hamed, K.H.; Rao, A.R. A modified Mann-Kendall trend test for autocorrelated data. J. Hydrol. 1998, 204, 182-196. [CrossRef]

52. Sayemuzzaman, M.; Jha, M.K. Seasonal and annual precipitation time series trend analysis in North Carolina, United States. Atmos. Res. 2014, 137, 183-194. [CrossRef]

53. Jiang, W.; Yuan, L.; Wang, W.; Cao, R.; Zhang, Y.; Shen, W. Spatio-temporal analysis of vegetation variation in the Yellow River Basin. Ecol. Indic. 2015, 51, 117-126. [CrossRef]

54. Li, X.; Gong, P.; Zhou, Y.; Wang, J.; Bai, Y.; Chen, B.; Hu, T.; Xiao, Y.; Xu, B.; Yang, J. Mapping global urban boundaries from the global artificial impervious area (GAIA) data. Environ. Res. Lett. 2020, 15, 094044. [CrossRef]

55. Nolte, C.; Agrawal, A.; Barreto, P. Setting priorities to avoid deforestation in Amazon protected areas: Are we choosing the right indicators? Environ. Res. Lett. 2013, 8, 015039. [CrossRef]

56. Liu, X.; Huang, Y.; Xu, X.; Li, X.; Li, X.; Ciais, P.; Lin, P.; Gong, K.; Ziegler, A.D.; Chen, A. High-spatiotemporal-resolution mapping of global urban change from 1985 to 2015. Nat. Sustain. 2020, 4, 1-7. [CrossRef]

57. Isobe, S. Japanese Government Official Guideline for Reduction of Light Pollution; Symposium-International Astronomical Union, Cambridge University Press: Cambridge, UK, 2001; pp. 117-119.

58. Du, M.; Wang, L.; Zou, S.; Shi, C. Modeling the census tract level housing vacancy rate with the Jilin1-03 satellite and other geospatial data. Remote Sens. 2018, 10, 1920. [CrossRef]

59. Falchi, F.; Furgoni, R.; Gallaway, T.A.; Rybnikova, N.A.; Portnov, B.A.; Baugh, K.; Cinzano, P.; Elvidge, C.D. Light pollution in USA and Europe: The good, the bad and the ugly. J. Environ. Manag. 2019, 248, 109227. [CrossRef]

60. Kyba, C.C. Is light pollution getting better or worse? Nat. Astron. 2018, 2, 267-269. [CrossRef]

61. Zielinska-Dabkowska, K.M.; Xavia, K.; Bobkowska, K. Assessment of Citizens' Actions against Light Pollution with Guidelines for Future Initiatives. Sustainability 2020, 12, 4997. [CrossRef]

62. Lyytimäki, J. Nature's nocturnal services: Light pollution as a non-recognised challenge for ecosystem services research and management. Ecosyst. Serv. 2013, 3, e44-e48. [CrossRef]

63. Salmon, M.; Tolbert, M.G.; Painter, D.P.; Goff, M.; Reiners, R. Behavior of loggerhead sea turtles on an urban beach. II. Hatchling orientation. J. Herpetol. 1995, 29, 568-576. [CrossRef]

64. Lao, S.; Robertson, B.A.; Anderson, A.W.; Blair, R.B.; Eckles, J.W.; Turner, R.J.; Loss, S.R. The influence of artificial light at night and polarized light on bird-building collisions. Biol. Conserv. 2020, 241, 108358. [CrossRef]

65. Venter, O.; Sanderson, E.W.; Magrach, A.; Allan, J.R.; Beher, J.; Jones, K.R.; Possingham, H.P.; Laurance, W.F.; Wood, P.; Fekete, B.M. Sixteen years of change in the global terrestrial human footprint and implications for biodiversity conservation. Nat. Commun. 2016, 7, 1-11. [CrossRef] [PubMed]

66. Williams, D.R.; Clark, M.; Buchanan, G.M.; Ficetola, G.F.; Rondinini, C.; Tilman, D. Proactive conservation to prevent habitat losses to agricultural expansion. Nat. Sustain. 2020, 4, 314-322. [CrossRef]

67. Shrestha, N.; Xu, X.; Meng, J.; Wang, Z. Vulnerabilities of protected lands in the face of climate and human footprint changes. Nat. Commun. 2021, 12, 1-9. [CrossRef] [PubMed]

68. Bará, S.; Rigueiro, I.; Lima, R.C. Monitoring transition: Expected night sky brightness trends in different photometric bands. J. Quant. Spectrosc. Radiat. Transf. 2019, 239, 106644. [CrossRef]

69. de Miguel, A.S.; Kyba, C.C.; Aubé, M.; Zamorano, J.; Cardiel, N.; Tapia, C.; Bennie, J.; Gaston, K.J. Colour remote sensing of the impact of artificial light at night (I): The potential of the International Space Station and other DSLR-based platforms. Remote Sens. Environ. 2019, 224, 92-103. [CrossRef]

70. Aubé, M.; Roby, J.; Kocifaj, M. Evaluating potential spectral impacts of various artificial lights on melatonin suppression, photosynthesis, and star visibility. PLoS ONE 2013, 8, e67798. [CrossRef]

71. Gong, P.; Li, X.; Wang, J.; Bai, Y.; Chen, B.; Hu, T.; Liu, X.; Xu, B.; Yang, J.; Zhang, W. Annual maps of global artificial impervious area (GAIA) between 1985 and 2018. Remote Sens. Environ. 2020, 236, 111510. [CrossRef]

72. Gong, P.; Li, X.; Zhang, W. 40-Year (1978-2017) human settlement changes in China reflected by impervious surfaces from satellite remote sensing. Sci. Bull. 2019, 64, 756-763. [CrossRef]

73. Li, X.; Gong, P.; Liang, L. A 30-year (1984-2013) record of annual urban dynamics of Beijing City derived from Landsat data. Remote Sens. Environ. 2015, 166, 78-90. [CrossRef]

74. Kocifaj, M.; Kundracik, F.; Barentine, J.C.; Bará, S. Opacity Project data on CD for mean opacities and radiative accelerations. Mon. Not. R. Astron. Soc. 2021, 504, L40-L44. [CrossRef] 